attempted to clarify the relation. ${ }^{3}{ }^{16-19}$ Taiwan, as well as other newly industrialised countries blessed with a rapid economic transition, should provide a good opportunity for further work to understand mechanisms linking income inequality to health.

\section{Conclusion}

The health of the population is affected more by income distribution than by the level of income after a country has changed from a developing to a developed economy. Thus, a newly developed country such as Taiwan should pay more attention to the consequences on population health of the gap between the rich and the poor and not merely healthcare reform..$^{20}$

I thank Shu-Chen Liu, Shao-I Lin, and Tsung-Hsueh Lu for their help in data processing.

Funding: None.

Competing interests: None declared.

1 Wilkinson RG. Income distribution and life expectancy. BMJ 1992;304:165-8.

2 Wilkinson RG. Unhealthy societies: the afflictions of inequality. London: Routledge, 1996.

3 Kaplan GA, Pamuk E, Lynch JW, Cohen RD, Balfour JL. Inequality in income and mortality in the United States: analysis of mortality and potential pathways. BMJ 1996:312:999-1003.

4 Kennedy BP, Kawachi I, Prothrow-Stith D. Income distribution and mortality: cross sectional ecological study of the Robin Hood index in the United States. BMJ 1996;312:1004-7. [Important correction BMJ 1996;312:1194.]

5 Republic of China Council for Economic Planning and Development Taiwan statistical data book, 1998. Taipei: Council for Economic Planning and Development, 1998.

$6 \mathrm{Li}$ KT. The evolution of policy behind Taiwan's development success. New Haven: Yale University Press, 1988.

7 Kuo SWY, Ranis G, Fei JCH. The Taiwan success story: rapid growth with improved distribution in the Republic of China, 1952-1979. Boulder, CO: Westerview, 1981.

8 Republic of China Department of Health. Health and vital statistics, vol I. General health statistics, 1997. Taipei: Department of Health, 1998.

9 Republic of China, Ministry of the Interior. Taiwan-Fukien demographic fact book (published annually). Taipei: Ministry of the Interior. (Sources: 1973, $1976,1985,1995$ )

10 Armitage P, Berry G. Statistical methods in medical research, 3rd ed. Oxford: Blackwell Scientific, 1994.
Key messages

- Income distribution may be more important than the level of income in determining population health in developed countries but has not been examined in a country through different stages of economic development

- Along with economic development, gross national product per capita in Taiwan has increased rapidly from less than US\$200 (£72) in 1953 to US\$1132 (£627) in 1976 and to US\$12 396 (£7853) in 1995

- In Taiwan the association between income distribution and mortality was stronger in 1995 than in 1976, contrary to the association between absolute income and mortality, which was stronger in 1976 than in 1995

- The effect of income distribution on age specific mortality rate in children under 5 became highly significant whereas the effect of absolute income became non-significant in 1995

11 Goldstone LA. Understanding medical statistics. London: William Heinemann Medical, 1983

12 Wilkinson RG. Health inequalities: relative or absolute material standards? BMJ 1997;314:591-5.

13 Kuznets S. Economic growth and income inequality. Am Econ Rev 1955;45:1-28.

14 Davey Smith G, Egger M. Commentary: understanding it all-health, meta-theories, and mortality trends. BMJ 1996;313:1584-5.

15 Kaplan GA, Lynch JW. Whither studies on socioeconomic foundations of population health. Am J Public Health 1997;87:1409-11.

16 Kawachi I, Kennedy BP, Lochner K, Prothrow-Stith D. Social capital, income inequality, and mortality. Am J Public Health 1997;87:1491-8.

17 Wilkinson RG, Kawachi I, Kennedy BP. Mortality, the social environment, crime and violence. Sociol Health Ill 1998;20:578-97.

18 Daly MC, Duncan GJ, Kaplan, Lynch JW. Macro-to-micro links in the relation between income inequality and mortality. Milbank $Q$ 1998; 76:339.

19 Wallberg P, McKee M, Shkolnikov V, Chenet L, Leon DA. Economic change, crime, and mortality crisis in Russia: regional analysis. $B M J$ 1998;317:312-8.

20 Chiang TL. Taiwan's 1995 health care reform. Health Policy 1997;39: 225-39.

(Accepted 29July 1999)

\title{
Visual field defect associated with vigabatrin: observational cohort study
}

\author{
L V Wilton, M D B Stephens, R D Mann
}

Since Eke et al's report of persistent visual field constriction associated with vigabatrin, ${ }^{1}$ several letters have been published in the BMJ, including that by Mackenzie and Klistorner, ${ }^{2}$ that draw attention to the occurrence of visual field changes in asymptomatic patients as well as those with symptoms.

\section{Subjects, methods, and results}

A prescription event monitoring study of vigabatrin conducted between 1991 and 1994 identified four cases of bilateral, persistent visual field defect for which there was objective evidence and no alternative cause given. ${ }^{3}$ The study cohort consisted of 10033 living patients for whom questionnaires containing clinical information were returned (table). The mean duration of treatment for these four cases was 19.8 months; for the total cohort it was 14.2 months. Subsequently, we were informed of another seven patients in this cohort in whom visual field defect had been reported after the end of the study's observation period. This suggested that further cases might be identified if the period of observation was extended. ${ }^{4}$

The 7228 patients who were still taking vigabatrin at the end of the study were followed up by sending a simple questionnaire to their general practitioner to ask if vigabatrin treatment was continuing and whether any serious adverse events or changes in vision had been reported since the questionnaire had been returned. If patients had been referred for visual problems, the ophthalmologist was asked to complete a questionnaire giving details of visual field testing before and during treatment with vigabatrin, to comment on the possible cause of the defect, and to send copies of test results.

The results of both studies are shown in the table. Altogether 2068 of the returned questionnaires were not considered further because they did not contain 
Cases of visual field defect attributed to treatment with vigabatrin in prescription event monitoring study 1991-4 and long term follow up study 1998-9

\begin{tabular}{ll}
\hline Prescription event monitoring study & No (\%) cases \\
\hline Questionnaires sent & $17307(100)$ \\
\hline Questionnaires returned & $11769(68)$ \\
\hline Questionnaires with clinical data & $10178(59)$ \\
\hline Questionnaires with clinical data, for living patients & $10033(58)$ \\
\hline In these 10 033 living patients:- & $4(0.04)$ \\
\hline Patients with objective evidence of visual field defect & $7228(100)$ \\
\hline Long term follow up study & $6809(94)$ \\
\hline $\begin{array}{l}\text { Questionnaires sent for patients taking vigabatrin at end of prescription } \\
\text { event monitoring study }\end{array}$ & $5074(70)$ \\
\hline Questionnaires returned & $4741(66)$ \\
\hline Questionnaires with clinical data* & $36(0.8)$ \\
\hline Questionnaires with clinical data, for living patients & $14(0.3)$ \\
\hline In these 4741 living patients: & $16(0.3)$ \\
\hline Objective evidence of visual field defect & \\
\hline Visual field defect "probably" associated with vigabatrin & \\
\hline Visual field defect "possibly" associated with vigabatrin† & \\
\hline
\end{tabular}

*Patients no longer registered with general practitioner=1136; blank questionnaires or duplicate patients $=599$.

†Includes one case from the prescription event monitoring study.

clinical data (1735) or the patients had died (333). In the surviving 4741 patients, 89 reports were followed up with ophthalmologists.

The ophthalmologists consider that $30(83 \%)$ of the 36 cases for which there is objective evidence of visual field defect are probably or possibly related to vigabatrin. In four cases they did not know whether the defect was related to vigabatrin treatment, and in the remaining two cases the defect was considered not to be due to vigabatrin. The mean age at the time of diagnosis for the 19 men was 45.7 years (range 20-64), and for the 11 women it was 37.6 years (range 20-56). The mean duration of treatment to time of diagnosis in these 30 cases was 66.3 months (range 33-96).

In this second study information was requested on events reported after the original questionnaire was returned. One of the original four cases is also included in the 30 cases of the current study because visual field tests were carried out after the original questionnaire had been returned. In these two studies, 33 cases of visual field defect considered by ophthalmologists to be probably or possibly related to vigabatrin were identified, giving an incidence risk of 7.0 per 1000 patients $(33 / 4741)$. The minimal risk, based only on cases considered probably due to vigabatrin, is 3.4 per 1000 patients $(16 / 4741)$.

\section{Comment}

Although publicity bias may have influenced the number of patients referred for visual field tests since the original study, ${ }^{1-4}$ this substantial increase in the number of confirmed cases of visual field defect attributed to vigabatrin shows the clinical importance of this lesion in the long term use of vigabatrin. We have also shown that signals of long latency adverse drug reactions identified in a prescription event monitoring study can be successfully investigated in a long term follow up study.

We thank all the general practitioners and hospital doctors who have taken part in these two studies. We also thank Jackie Barfoot for her help in coordinating the study.

Contributors: LVW participated in the study design and the follow up questionnaire, was responsible for the execution and coordination of the study, analysis and interpretation of data, and writing the short report. MDBS identified and validated the original cases, participated in formulating the design of the follow up study and the questionnaire, and contributed to writing the paper. RDM participated in study design and interpretation of results and edited the short report. RDM will act as guarantor.

Funding: None.

Competing interests: None declared.

1 Eke T, Talbot JF, Lawden MC. Severe persistent visual field constriction associated with vigabatrin. $B M J$ 1997;314:180-1.

2 Mackenzie R, Klistorner A. Asymptomatic as well as symptomatic defects occur with vigabatrin. BMJ 1998;316:233.

3 Mann RD. Prescription-event monitoring-recent progress and future horizons. Br J Clin Pharmacol 1998;46:195-201.

4 Committee on Safety of Medicines, Medicines Control Agency. Vigabatrin (Sabril) and visual field defects. Current problems in pharmacovigilance. 1998;24:1
Hôpital Robert Debré, Institut

National de la Santé et de la Recherche Medicale U458, F-75019 Paris

France

M Gabolde

paediatrician

C Besmond

senior research fellow

continued over

BMJ 1999;319:1166-7
Prognosis of cystic fibrosis is conditioned by the severity of pulmonary damage, which is related to infectious complications. The group of $2 \mathrm{~F} 508$ homozygous patients with cystic fibrosis shows a substantial variability in clinical expression of the severity of lung disease, which could be explained by the influence of modulating genes ${ }^{1}$ that are probably related to the efficiency of host immune factors in fighting against infection in patients' lungs.

Mannose binding lectin, a protein of the innate immune system, is involved in opsonisation and phagocytosis of micro-organisms. The mannose binding lectin gene shows three major allelic variants that are responsible for a decrease of the protein plasma concentration, an opsonic defect, and a common immunodeficiency. ${ }^{2}$

We investigated the possible modulating role of mannose binding lectin because studies have shown (a) that homozygosity or compound heterozygosity for mannose binding lectin variant alleles predisposes to recurrent infections including lung infections and (b) that Staphyloccus aureus and Pseudomonas aeruginosa -the two most common and deleterious pathogens found in lung infections in patients with cystic fibrosis-have been cultured from patients deficient in this gene. ${ }^{3-4}$ 